\title{
Local structure relaxation in nanosized tungstates
}

\author{
A. Anspoks ${ }^{\mathrm{a}}$, A. Kalinko ${ }^{\mathrm{a}, \mathrm{b}}$, J. Timoshenko ${ }^{\mathrm{a}}$, A. Kuzmin ${ }^{\mathrm{a}, *}$ \\ ${ }^{a}$ Institute of Solid State Physics, University of Latvia, Kengaraga street 8, LV-1063 Riga, \\ Latvia \\ ${ }^{b}$ Synchrotron SOLEIL, l'Orme des Merisiers, Saint-Aubin, BP 48, 91192 Gif-sur-Yvette, \\ France
}

\section{Abstract}

The atomic structure of nanosized and microcrystalline tungstates $\mathrm{MeWO}_{4}$ $(\mathrm{Me}=\mathrm{Co}, \mathrm{Ni}, \mathrm{Cu}, \mathrm{Zn})$, synthesized by co-precipitation technique, has been studied by $\mathrm{x}$-ray absorption spectroscopy at the $\mathrm{W} \mathrm{L}_{3}$-edge and $\mathrm{Co} / \mathrm{Ni} / \mathrm{Cu} / \mathrm{Zn}$ K-edges, x-ray diffraction and Raman spectroscopy. The distortion of metaloxygen octahedra is caused by the electron-lattice coupling and is further enhanced in nanosized tungstates due to formation of the double tungstenoxygen bonds at the nanoparticle surface.

Keywords: A. Nanostructures; C. EXAFS; E. Synchrotron radiation; E. Inelastic light scattering

PACS: 81.07.Wx, 61.05.cj, 78.70.Dm

*Corresponding author. Tel.: +371672516 91; fax +371671327 78 .

Email address: a.kuzmin@cfi.lu.lv (A. Kuzmin)

URL: http://www.cfi.lv/ (A. Kuzmin) 


\section{Introduction}

The atomic structure of nanocrystalline materials differs from that in the bulk due to relaxation phenomena [1]. The unit-cell volume compression is common for metal nanoparticles [2,3], whereas its expansion occurs in most nanosized metal-oxides $[4,5]$. Since physical properties of nanoparticles are determined by their structure, an understanding of nanoscale lattice modifications is advantageous for properties tuning but is a challenging task $[6,7,8,9]$.

In this study we have explored a size-induced relaxation of the local structure in several tungstates by extended x-ray absorption fine structure (EXAFS) spectroscopy, x-ray powder diffraction and micro-Raman spectroscopy. Our recent results on nanosized $\mathrm{ZnWO}_{4}[10,11]$ have been extended to other tungstates $-\mathrm{CoWO}_{4}, \mathrm{NiWO}_{4}$ and $\mathrm{CuWO}_{4}$, thus, allowing us to elucidate in more details the effect of size, temperature and transition metal type.

\section{Experimental details}

Nanocrystalline powders were synthesized by co-precipitation method from aqueous solutions of $\mathrm{Na}_{2} \mathrm{WO}_{4} \cdot 2 \mathrm{H}_{2} \mathrm{O}$ and $\mathrm{Co}\left(\mathrm{NO}_{3}\right)_{2} \cdot 6 \mathrm{H}_{2} \mathrm{O}, \mathrm{Ni}\left(\mathrm{NO}_{3}\right)_{2} \cdot 6 \mathrm{H}_{2} \mathrm{O}$, $\mathrm{CuSO}_{4} \cdot 5 \mathrm{H}_{2} \mathrm{O}$ or $\mathrm{Zn}\left(\mathrm{NO}_{3}\right)_{2} \cdot 6 \mathrm{H}_{2} \mathrm{O}$ at room temperature $\left(20^{\circ} \mathrm{C}\right), \mathrm{pH}=8$ [10, 11]. Microcrystalline samples were obtained by annealing of nanopowders at $800^{\circ} \mathrm{C}$ for $4-8$ hours.

X-ray powder diffraction (XRD) patterns (Fig. 1) were recorded at $20^{\circ} \mathrm{C}$ using Bragg-Brentano powder diffractometer $(\theta / 2 \theta$ scans) equipped with conventional copper anode $(\mathrm{Cu} K \alpha)$ tube. 

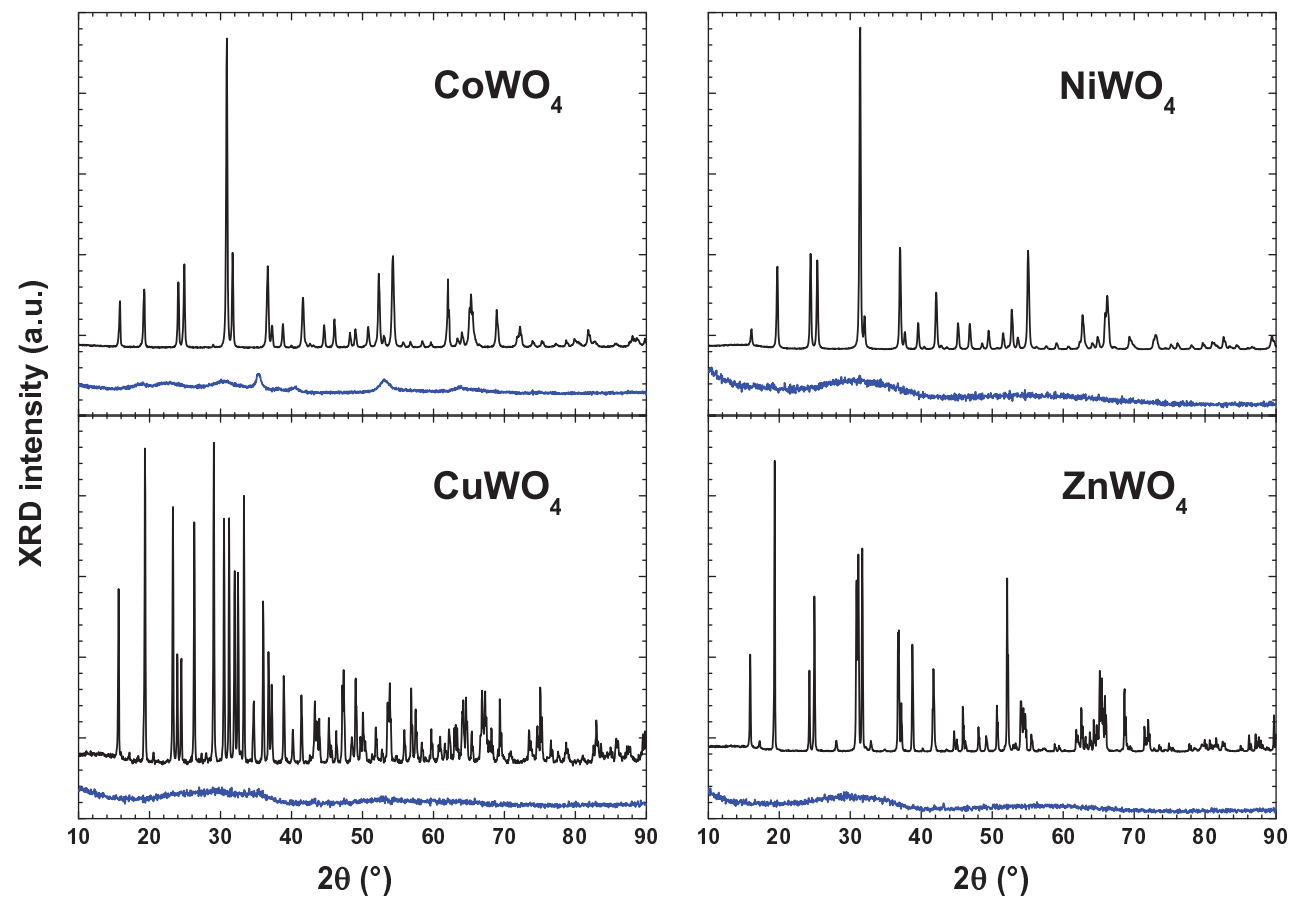

Figure 1: (Color online) X-ray diffraction patterns of as-prepared (lower curves) and annealed at $800^{\circ} \mathrm{C}$ (upper curves) $\mathrm{MeWO}_{4}(\mathrm{Me}=\mathrm{Co}, \mathrm{Ni}, \mathrm{Cu}, \mathrm{Zn})$ powders.

Micro-Raman scattering spectra (Fig. 2) were collected in back-scattering geometry at $20^{\circ} \mathrm{C}$ using a confocal microscope with spectrometer NanofinderS (SOLAR TII, Ltd.). The measurements were performed through Nikon Plan Apo 20× (NA=0.75) optical objective. DPSS laser $(532 \mathrm{~nm}, 150 \mathrm{~mW}$ $\mathrm{cw}$ power) was used as the excitation source, and the Raman scattering spectra were dispersed by 1800 grooves/mm diffraction grating, mounted in the $520 \mathrm{~mm}$ focal length monochromator. The elastic laser light component was eliminated by the edge filter (Semrock LP03-532RE). The Peltier-cooled back-thinned CCD camera (ProScan HS-101H) was used as a detector.

X-ray absorption measurements were performed in transmission mode at 
the HASYLAB/DESY C (CEMO) bending-magnet beamline [12] at the Co (7709 eV), Ni (8333 eV), Cu (8979 eV) and Zn (9659 eV) K-edges and W $\mathrm{L}_{3}(10207 \mathrm{eV})$ edge. The storage ring DORIS III operated at $E=4.44 \mathrm{GeV}$ and $I_{\max }=140 \mathrm{~mA}$. The x-ray beam intensity was measured by two ionization chambers filled with argon and krypton gases. The higher-order harmonics were effectively eliminated by detuning of the double-crystal monochromator $\mathrm{Si}(111)$ to $60 \%$ of the rocking curve maximum, using the beam-stabilization feedback control. The powder samples were deposited on Millipore filters and fixed by Scotch tape. The deposited powder weight was chosen to give the value of the absorption edge jump close to 1.0. Measurements were performed at 10 and $300 \mathrm{~K}$ using the Oxford Instruments liquid helium flow cryostat.

\section{EXAFS data analysis}

X-ray absorption spectra were analysed using the conventional procedure $[13,14]$. Fourier transforms (FTs) of the experimental EXAFS spectra $\chi(k) k^{2}$ at $T=300 \mathrm{~K}$ for $\mathrm{CoWO}_{4}$ and $\mathrm{CuWO}_{4}$ are shown in Fig. 3. The experimental data for $\mathrm{NiWO}_{4}$ and $\mathrm{ZnWO}_{4}$ were reported elsewhere $[15,16]$. The photoelectron wavenumber is defined as $k=\left[\left(2 m_{e} / \hbar^{2}\right)\left(E-E_{0}\right)\right]^{1 / 2}$, where $m_{e}$ is the electron mass, $\hbar$ is the Plank's constant, and $E_{0}$ is the photoelectron energy origin. The $E_{0}$ position in the experimental signals was set at the energy point to have the best match between $k$-space scales of the experimental and theoretical EXAFS spectra. Note that the positions of the FT peaks in Fig. 3 are shifted from their true crystallographic values because the FTs were calculated without phase-shift corrections. In this work only the first coordination shell contributions, singled out by the back-FT procedure 
in the range of $\simeq 0.8-2.2 \AA$, were analysed.

To extract structural information, the first shell EXAFS contributions $\chi(k) k^{2}$ were best-fitted using a model-independent approach $[17,18]$ allowing the reconstruction of the true radial distribution function (RDF) $G(R)$

$$
\chi(k)=\int_{R_{\text {min }}}^{R_{\max }} \frac{G(R)}{k R^{2}} F(\pi, k, R) \sin (2 k R+\Phi(\pi, k, R)) d R,
$$

where $R$ is the interatomic distance, $F(\pi, k, R)$ is the scattering amplitude function, and $\Phi(\pi, k, R)$ is the phase shift function. The obtained RDFs are shown in Fig. 4.

The advantage of the method provided by Eq. (1) is that the true RDF $G(R)$ can have an arbitrary (even strongly distorted) shape [17, 18]. This point is very important in the case of tungstates, especially nanocrystalline, where strong static distortion of the metal-oxygen octahedra is present [15], particularly in the case of $\mathrm{WO}_{6}$ and $\mathrm{CuO}_{6}$ octahedra experiencing strong Jahn-Teller distortion [19]. The significant distortion of octahedra makes the use of conventional EXAFS data analysis approach [13], i.e., an approximation of the RDF $G(R)$ by a set of Gaussian functions, inaccurate since such model is not able to account for an asymmetry of peaks in the RDF and is also not unique due to strong overlap between some peaks. However, the obtained RDFs can be utilized for the reconstruction of nanoparticle structure using advanced simulation techniques such as reverse Monte Carlo [20, 21] or Molecular Dynamics methods [9]. This problem is beyond the scope of the present manuscript and will be addressed by us in future work.

Note that the scattering amplitude $F(\pi, k, R)$ and phase shift $\Phi(\pi, k, R)$ functions, used in Eq. (1), were independently calculated for metal-oxygen atom pairs by ab initio real-space multiple-scattering code FEFF8 [22] using 


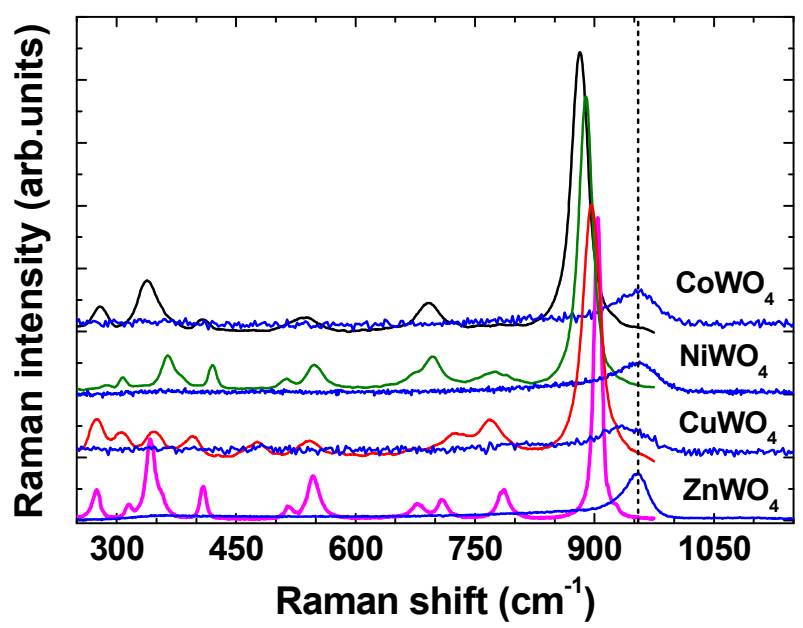

Figure 2: (Color online) Raman scattering spectra of microcrystaline and nanosized $\mathrm{MeWO}_{4}(\mathrm{Me}=\mathrm{Co}, \mathrm{Ni} \mathrm{Cu}, \mathrm{Zn})$ powders. The position of the main band at $955 \mathrm{~cm}^{-1}$ in nanosized tungstates is indicated by dashed vertical line. Measurements were performed at $20^{\circ} \mathrm{C}$.

the complex exchange-correlation Hedin-Lundqvist potential. The FEFF8 calculations were performed based on the crystallographic structure of tungstates $\left(\mathrm{CoWO}_{4}[23], \mathrm{NiWO}_{4}[24], \mathrm{CuWO}_{4}[25]\right.$ and $\left.\mathrm{ZnWO}_{4}[26,27]\right)$, considering a cluster of $8 \AA$ size around the absorbing metal atom. The size of the cluster allowed us to be confident in the accuracy of the calculated cluster potential and to simulate theoretical $\mathrm{W} \mathrm{L}_{3}$ and $\mathrm{Me}(\mathrm{Me}=\mathrm{Co}, \mathrm{Ni} \mathrm{Cu}, \mathrm{Zn}) \mathrm{K}$ edge EXAFS spectra, required for accurate evaluation of the $E_{0}$ values. Calculations of the cluster potentials were done in the muffin-tin (MT) self-consistentfield approximation using default values of MT radii as provided within the FEFF8 code [22]. 


\section{Results}

The XRD patterns for all as-prepared powders of tungstates have strongly broadened Bragg peaks (Fig. 1). Since the Raman scattering spectra of as-prepared powders are close and also strongly broadened (Fig. 2), and their EXAFS signals do not contain significant outer shell (beyond $\sim 4 \AA$ ) contributions (Fig. 3), we concluded that our samples are mainly composed of very fine (less than about $2 \mathrm{~nm}$ ) nanocrystallites [10, 11]. However, some larger nanocrystallites are present in $\mathrm{CoWO}_{4}$ sample and are responsible for a few small Bragg peaks in Fig. 1. Their relative amount is nevertheless small, so that they do not produce any observable contribution into Raman scattering and EXAFS spectra.

Note that the tungstate powders become microcrystalline upon annealing in air at $800^{\circ} \mathrm{C}$ [10], showing XRD patterns corresponding to respective wolframite phases with monoclinic $\left(\mathrm{CoWO}_{4}\right.$ [23], $\mathrm{NiWO}_{4}$ [24], $\left.\mathrm{ZnWO}_{4}[26,27]\right)$ or triclinic $\left(\mathrm{CuWO}_{4}[25]\right)$ symmetry.

The Raman scattering spectra of microcrystaline tungstates are shown in Fig. 2. Since they have two formula units $(Z=2)$ per primitive cell, the group theory analysis predicts 36 lattice modes, of which 18 even vibrations are Raman active $[19,28,29,30]$. Only twelve of them can be observed in the frequency range reported in Fig. 2. The position of the most intense band, located at $882-905 \mathrm{~cm}^{-1}$ and corresponding to the stretching $\mathrm{W}-\mathrm{O}$ vibration, shifts systematically to higher frequencies upon transition from $\mathrm{CoWO}_{4}$ to $\mathrm{ZnWO}_{4}$. The Raman scattering spectra of nanoparticles differ significantly from that in microcrystalline powders. They are dominated by one broad band, located at $\sim 955 \mathrm{~cm}^{-1}$. One should note that a care should be taken 
when measuring the Raman scattering from tungstate nanoparticles, since they can be easily crystallized under excessive laser irradiation.

Fourier transforms of the experimental $\mathrm{W} \mathrm{L}_{3}$ and $\mathrm{Co}(\mathrm{Cu}) \mathrm{K}$ edges EXAFS spectra $\chi(k) k^{2}$ are shown in Fig. 3. The amplitude of all peaks, especially beyond the first one, is strongly reduced in nanopowders, as expected. The effect is more pronounced at the $\mathrm{W} \mathrm{L}_{3}$-edge, indicating stronger relaxation of tungsten environment. The RDFs for the first coordination shell around metal atoms were extracted, as described in Section (3), from the first peak in FTs and are shown in Fig. 4 for all microcrystalline (solid lines) and nanosized (dashed lines) tungstates. They correspond to the distribution of oxygen atoms within metal-oxygen octahedra. A comparison of the RDFs obtained at 10 and $300 \mathrm{~K}$ in $\mathrm{CuWO}_{4}$ suggests that the effect of thermal disorder leads to some peak broadening and is relatively small, in particular, in nanopowders where static relaxation dominates.

In microcrystalline $\mathrm{CoWO}_{4}[23]$ and $\mathrm{NiWO}_{4}[24]$ the six oxygen atoms of slightly distorted $\mathrm{Co}(\mathrm{Ni}) \mathrm{O}_{6}$ octahedra contribute into one broad peak, centered at $\sim 2.08 \AA$ in the $\operatorname{RDF} G_{\mathrm{Co}-\mathrm{O}}(R)$ and at $\sim 2.05 \AA$ in the $\mathrm{RDF}$ $G_{\mathrm{Ni}-\mathrm{O}}(R)$, respectively. The $\mathrm{WO}_{6}$ octahedra in both tungstates are strongly distorted: the six oxygens are divided into two groups of four (at $\sim 1.83 \AA$ ) and two (at $\sim 2.15 \AA$ ) atoms.

In microcrystalline $\mathrm{CuWO}_{4}[25]$ the $\mathrm{RDF} G_{\mathrm{Cu}-\mathrm{O}}(R)$ is split into two peaks, composed of four and two oxygen atoms. At the same time, the distortion of $\mathrm{WO}_{6}$ octahedra is the strongest one among all four tungstates: six oxygen atoms are divided into 3 groups of three (at $\sim 1.81 \AA$ ), two (at $\sim 2.02 \AA$ ) and one (at $\sim 2.20 \AA$ ) atoms. 
The distortion of metal-oxygen octahedra in microcrystalline $\mathrm{ZnWO}_{4}[26$, 27] is stronger than in $\mathrm{CoWO}_{4}$ and $\mathrm{NiWO}_{4}$, but weaker than in $\mathrm{CuWO}_{4}$. The oxygen atoms in both $\mathrm{ZnO}_{6}$ and $\mathrm{WO}_{6}$ octahedra are divided into three groups of two oxygen atoms each. The group of nearest four oxygens is responsible for a single peak at $\sim 2.02 \AA$ in the $\operatorname{RDF} G_{\mathrm{Zn}-\mathrm{O}}(R)$, whereas remaining two oxygens give rise to the peak at $\sim 2.25 \AA$. In the case of the $\operatorname{RDF} G_{\mathrm{W}-\mathrm{O}}(R)$, the three groups of oxygen atoms are well resolved and contribute into the three peaks at $\sim 1.80 \AA, \sim 1.95 \AA$ and $\sim 2.14 \AA$, respectively.

In nanosized tungstates, the $\mathrm{RDFs} G_{\mathrm{Me}-\mathrm{O}}(R)$ are more broadened. Besides, the distortion of $\mathrm{ZnO}_{6}$ octahedra becomes stronger in nano- $\mathrm{ZnWO}_{4}$, leading to further separation of nearest four and distant two oxygen atoms. The modification of the RDFs $G_{\mathrm{W}-\mathrm{O}}(R)$ is more dramatic. The distortion of $\mathrm{WO}_{6}$ octahedra increases in all tungstates in such a way that the nearest four oxygen atoms move slightly closer, whereas the distant two oxygens move away. This effect is most evident in the $\operatorname{RDFs}_{\mathrm{W}-\mathrm{O}}(R)$ for nanosized $\mathrm{NiWO}_{4}, \mathrm{CoWO}_{4}$ and $\mathrm{ZnWO}_{4}$.

\section{Discussion}

The absence of Bragg peaks in XRD patterns of nanoparticles (Fig. 1) suggests that the size of crystallites in as-prepared powders is below $2 \mathrm{~nm}$. Taking into account nanoparticles stoichiometry, the size of metal-oxygen octahedra $(\sim 4 \AA)$ and their connectivity in crystalline tungstates, one can conclude that nanoparticles are built up of just a few metal-oxygen octahedra.

Chemical bonding in microcrystalline tungstates can be successfully probed 

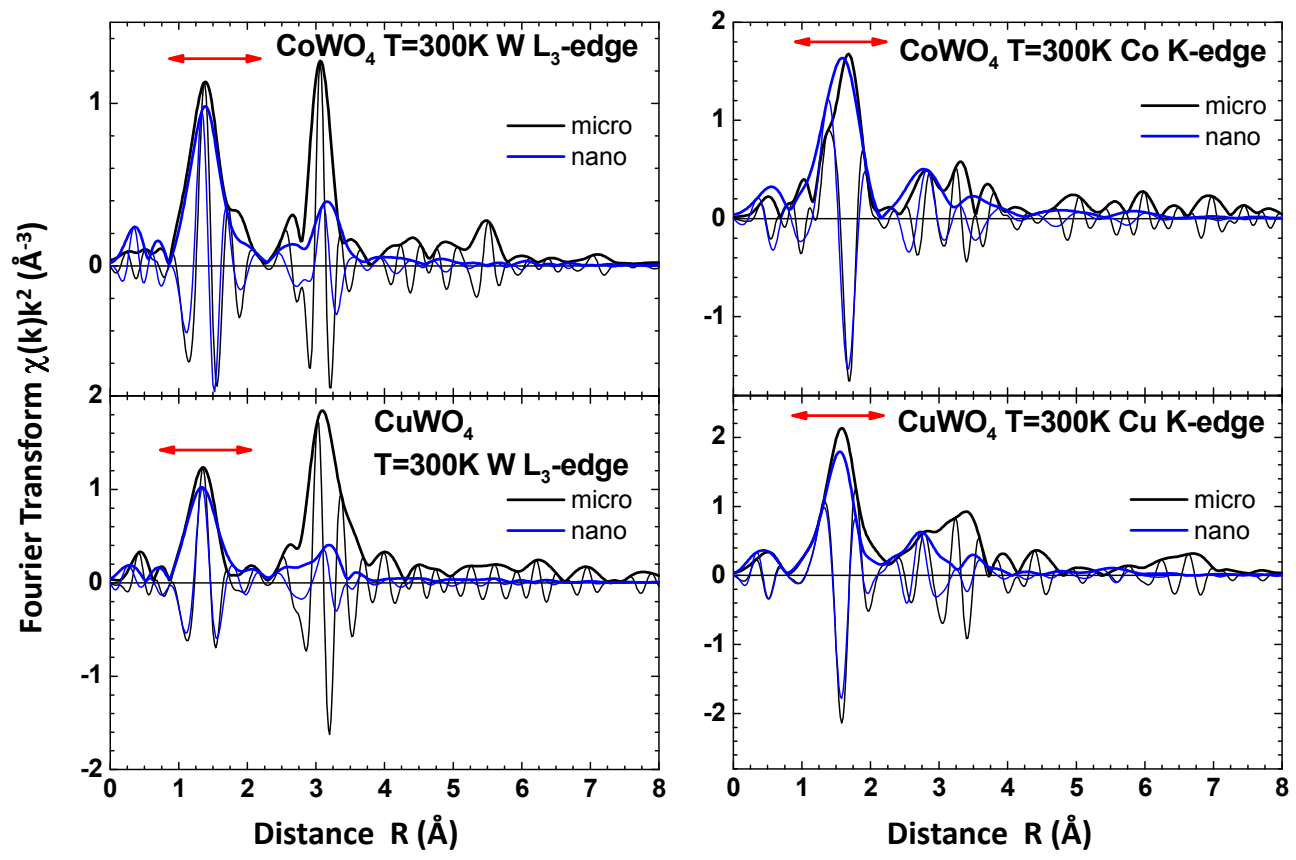

Figure 3: (Color online) Fourier transforms (FTs) of the experimental $\mathrm{W} \mathrm{L}_{3}$ and $\mathrm{Co}(\mathrm{Cu})$ $\mathrm{K}$ edges EXAFS spectra $\chi(k) k^{2}$ for microcrystalline and nanoparticles $\mathrm{Co}(\mathrm{Cu}) \mathrm{WO}_{4}$ at $T=300 \mathrm{~K}$. Both modulus and imaginary parts of FTs are shown.

by Raman spectroscopy, providing an access to the half of vibrational modes (Fig. 2). An increase of the stretching $\mathrm{W}-\mathrm{O}$ frequency from $882 \mathrm{~cm}^{-1}$ in $\mathrm{CoWO}_{4}$ to $905 \mathrm{~cm}^{-1}$ in $\mathrm{ZnWO}_{4}$ indicates some strengthening of tungstenoxygen bonds [31], which compete with the Me-O bonding. Note that the corresponding $\mathrm{W}-\mathrm{O}$ bond lengths are almost equal $(\sim 1.79 \AA)$ in the four tungstates $[23,24,25,26,27]$.

Nanosized tungstates are much weaker Raman scatterers (Fig. 2): the only visible broad band at $\sim 955 \mathrm{~cm}^{-1}$ was attributed previously to the double tungsten-oxygen $\mathrm{W}=\mathrm{O}$ bonds at the nanoparticle surface [10]. The band 

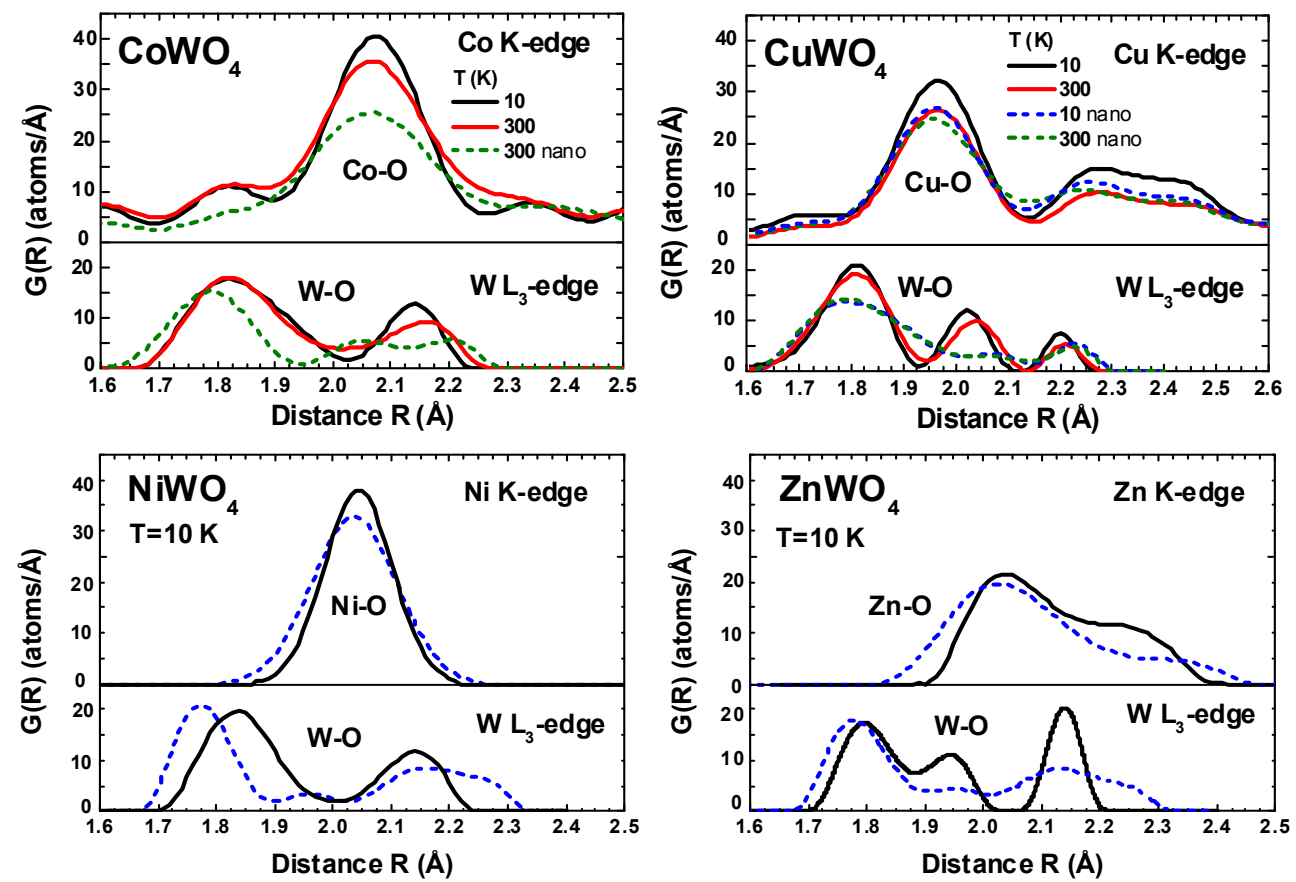

Figure 4: (Color online) The reconstructed RDFs $G(R)$ for the first coordination shell of tungsten and transition metals in microcrystalline (solid lines) and nanosized (dashed lines) $\mathrm{MeWO}_{4}(\mathrm{Me}=\mathrm{Co}, \mathrm{Ni}, \mathrm{Cu}, \mathrm{Zn})$. See text for details.

has a single-peak shape in $\mathrm{CoWO}_{4}, \mathrm{NiWO}_{4}$ and $\mathrm{ZnWO}_{4}$, but has more complex structure in $\mathrm{CuWO}_{4}$, suggesting the presence of slightly inequivalent non-bridging $\mathrm{W}=\mathrm{O}$ bonds. A well known correlation [31] between the force constant (or stretching frequency) and the length of the $\mathrm{W}-\mathrm{O}$ bond suggests the $\mathrm{W}=\mathrm{O}$ bond length of about $1.7 \AA$.

In fact, the existence of short tungsten-oxygen bonds in nanopowders is clearly visible in the RDFs $G_{\mathrm{W}-\mathrm{O}}(R)$ (Fig. 4). In general, the $\mathrm{WO}_{6}$ octahedra distortion originates from strong electron-lattice coupling, which leads to the second-order Jahn-Teller (SOJT) effect due to a covalent interaction of 
empty $5 d$ orbitals in $\mathrm{W}^{6+}$ ions with filled $2 p$ orbitals in the oxygen atoms [32]. An additional contribution into the $\mathrm{WO}_{6}$ octahedron deformation comes from competing interaction of oxygens with the $3 d$ transition metal ions. It manifests most strongly in $\mathrm{CuWO}_{4}$, where the axial distortion of $\mathrm{CuO}_{6}$ octahedra is stabilized by the first-order Jahn-Teller (FOJT) effect caused by the $3 d^{9}$ electron configuration of $\mathrm{Cu}^{2+}$ ions $[19,33,34,35]$. As a result, the RDFs $G_{\mathrm{Cu}-\mathrm{O}}(R)$ have close shape in both microcrystalline and nanosized powders, and the difference between the RDFs $G_{\mathrm{W}-\mathrm{O}}(R)$ is caused mainly by peak broadening.

In $\mathrm{CoWO}_{4}, \mathrm{NiWO}_{4}$ and $\mathrm{ZnWO}_{4}$, the bonding between $3 d$ and oxygen ions is less rigid, so that their local environment is able to relax in nanopowders, giving more freedom to tungsten ions to adapt themselves. Therefore, tungsten ions are able to attract four nearest oxygens, thus enhancing the distortion of $\mathrm{WO}_{6}$ octahedra. The remaining two oxygen atoms are weakly bonded to tungsten and are responsible for the distant peak in the RDF at $\sim 2.1-2.3 \AA$ (Fig. 4). Such value of the tungsten-oxygen bonds is typical for $\mathrm{W}-\mathrm{OH}_{2}$ bonding in hydrates $\mathrm{WO}_{3} \cdot \mathrm{nH}_{2} \mathrm{O}[31,36]$ and for $\mathrm{W}-\mathrm{OH}$ bonds at the tungsten oxide surface [37]. Note that in hydrates the $\mathrm{W}-\mathrm{OH}_{2}$ bonds are located opposite to the short terminal $\mathrm{W}=\mathrm{O}$ bonds [31], discussed above. The presence of $\mathrm{OH}$ groups or $\mathrm{H}_{2} \mathrm{O}$ molecules in our nanocrystalline powders follows from the synthesis procedure (see Sec. (2)) and is required to maintain nanoparticle electroneutrality. Unfortunately, hydrogen atoms cannot be reliably detected in EXAFS spectra, whereas their contribution into Raman scattering spectra of nanopowders is masked by strong band broadening. 


\section{Conclusions}

The analysis of the $\mathrm{W} \mathrm{L}_{3}$-edge and $\mathrm{Me}(\mathrm{Me}=\mathrm{Co}, \mathrm{Ni}, \mathrm{Cu}, \mathrm{Zn}) \mathrm{K}$-edge EXAFS spectra by the regularization-like method has allowed us to reliably determine a distortion of $\mathrm{WO}_{6}$ and $\mathrm{MeO}_{6}$ octahedra in microscrystalline and nanosized tungstates. The distortion is caused by the electron-lattice coupling, which depends on the electronic structure of $\mathrm{Me}^{2+}$ and $\mathrm{W}^{6+}$ ions. Additional structure relaxation in nanosized tungstates induces further deformation of the octahedra and a formation of the double tungsten-oxygen bonds, being responsible for the broad band at $\sim 955 \mathrm{~cm}^{-1}$ in Raman scattering spectra.

The obtained information on the structure relaxation in nanosized tungstates is relevant for understanding and tuning of their functional properties $[15$, $38,39]$.

\section{Acknowledgements}

This study was supported by European Social Fund ("Support for Doctoral Studies at University of Latvia) and Latvian Science Council Grant No. 187/2013. The EXAFS experiments at HASYLAB/DESY were supported by the EC FP7 under grant agreement No. 226716.

\section{References}

[1] C. Q. Sun, Prog. Solid State Chem. 35 (2007) 1.

[2] P. A. Montano, G. K. Shenoy, E. E. Alp, W. Schulze, J. Urban, Phys. Rev. Lett. 56 (1986) 2076. 
[3] R. Lamber, S. Wetjen, N. I. Jaeger, Phys. Rev. B 51 (1995) 10968.

[4] M. Fukuhara, Phys. Lett. A. 313 (2003) 427.

[5] G. Li, J. Boerio-Goates, B. F. Woodfield, L. Li, Appl. Phys. Lett. 85 (2004) 2059.

[6] A. Witkowska, A. Di Cicco, E. Principi, Phys. Rev. B 76 (2007) 104110.

[7] A. I. Frenkel, A. Yevick, C. Cooper, R. Vasic, Annu. Rev. Anal. Chem. 4 (2011) 23.

[8] G. Greco, A. Witkowska, E. Principi, M. Minicucci, A. Di Cicco, Phys. Rev. B 83 (2011) 134103.

[9] A. Anspoks, A. Kalinko, R. Kalendarev, A. Kuzmin, Phys. Rev. B 86 (2012) 174114.

[10] A. Kalinko, A. Kuzmin, J. Lumin. 129 (2009) 1144.

[11] A. Kalinko, A. Kotlov, A. Kuzmin, V. Pankratov, A. I. Popov, L. Shirmane, Centr. Eur. J. Phys. 9 (2011) 432.

[12] K. Rickers, W. Drube, H. Schulte-Schrepping, E. Welter, U. Bruggmann, M. Herrmann, J. Heuer, H. Schulz-Ritter, AIP Conf. Proc. 882 (2007) 905 .

[13] V. L. Aksenov, A. Y. Kuzmin, J. Purans, S. I. Tyutyunnikov, Phys. Part. Nucl. 32 (2001) 675.

[14] A. Kuzmin, Physica B 208-209 (1995) 175. 
[15] A. Kalinko, A. Kuzmin, J. Non-Cryst. Solids 357 (2011) 2595.

[16] A. Kuzmin, V. Pankratov, A. Kalinko, A. Kotlov, L. Shirmane, A. I. Popov, J. Phys. Conf. Ser. (accepted) (2013).

[17] A. Kuzmin, J. Phys. IV (France) 7 (1997) C2-213.

[18] A. Kuzmin, J. Purans, J. Phys.: Condens. Matter 12 (2000) 1959.

[19] A. Kuzmin, A. Kalinko, R. Evarestov, Acta Mater. 61 (2013) 371.

[20] N. Bedford, C. Dablemont, G. Viau, P. Chupas, V. Petkov, J. Phys. Chem. C 111 (2007) 18214.

[21] J. Timoshenko, A. Kuzmin, J. Purans, Comp. Phys. Commun. 183 (2012) 1237.

[22] A. L. Ankudinov, B. Ravel, J. J. Rehr, S. D. Conradson, Phys. Rev. B 58 (1998) 7565.

[23] J. B. Forsyth, C. Wilkinson, J. Phys.: Condens. Matter 6 (1994) 3073.

[24] H. Weitzel, Z. Kristallogr. 144 (1976) 238.

[25] J. B. Forsyth, C. Wilkinson, A. I. Zvyagin, J. Phys.: Condens. Matter 3 (1991) 8433.

[26] P. F. Schofield, K. S. Knight, G. Cressey, J. Mater. Sci. A 31 (1996) 2873.

[27] D. M. Trots, A. Senyshyn, L. Vasylechko, R. Niewa, T. Vad, V. B. Mikhailik, H. Kraus, J. Phys.: Condens. Matter 21 (2009) 325402. 
[28] Y. Liu, H. Wang, G. Chen, Y. D. Zhou, B. Y. Gu, B. Q. Hu, J. Appl. Phys. 64 (1988) 4651.

[29] H. Wang, F. D. Medina, Y. D. Zhou, Q. N. Zhang, Phys. Rev. B 45 (1992) 10356.

[30] A. Kuzmin, A. Kalinko, R. A. Evarestov, Centr. Eur. J. Phys. 9 (2011) 502.

[31] M. F. Daniel, B. Desbat, J. C. Lassegues, B. Gerand, M. Figlarz, J. Solid State Chem. 67 (1987) 235.

[32] M. Kunz, I. Brown, J. Solid State Chem. 115 (1995) 395.

[33] J. Ruiz-Fuertes, D. Errandonea, R. Lacomba-Perales, A. Segura, J. González, F. Rodríguez, F. J. Manjón, S. Ray, P. RodríguezHernández, A. Muñoz, Z. Zhu, C. Y. Tu, Phys. Rev. B 81 (2010) 224115.

[34] J. Ruiz-Fuertes, A. Friedrich, J. Pellicer-Porres, D. Errandonea, A. Segura, W. Morgenroth, E. Haussühl, C.-Y. Tu, A. Polian, Chem. Mater. 23 (2011) 4220.

[35] J. Ruiz-Fuertes, A. Segura, F. Rodríguez, D. Errandonea, M. N. SanzOrtiz, Phys. Rev. Lett. 108 (2012) 166402.

[36] M. Gotić, M. Ivanda, S. Popović, S. Musić, Mater. Sci. Eng. B - Adv. $77(2000) 193$.

[37] A. Kuzmin, J. Purans, E. Cazzanelli, C. Vinegoni, G. Mariotto, J. Appl. Phys. 84 (1998) 5515. 
Published in Solid State Communications 183 (2014) 22-26.

[38] S. M. Montemayor, A. F. Fuentes, Ceram. Int. 30 (2004) 393.

[39] P. Schmitt, N. Brem, S. Schunk, C. Feldmann, Adv. Funct. Mater. 21 (2011) 3037. 


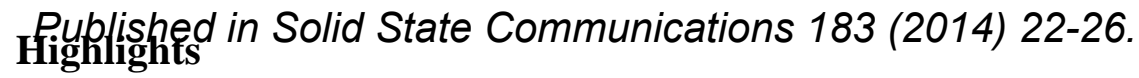

- $\mathrm{MeWO}_{4}(\mathrm{Me}=\mathrm{Co}, \mathrm{Ni}, \mathrm{Cu}, \mathrm{Zn})$ were prepared by co-precipitation method.

- Local structure of $\mathrm{MeWO}_{4}$ was studied by Raman and x-ray absorption spectroscopy.

- The atomic structure of nanocrystalline $\mathrm{MeWO}_{4}$ is strongly relaxed.

- Distortion of metal-oxygen octahedra is caused by the electron-lattice coupling. 